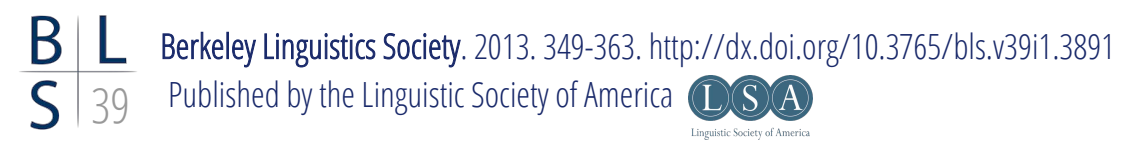

\title{
Here and Now: Mapping Space and Time in a Four-Part Frame of Reference Typology
}

\author{
EVE DANZIGER \\ University of Virginia
}

\section{$1 \quad$ Introduction $^{1}$}

In many languages, terminology which was originally devoted purely to space also serves in the expression of temporal or other relations (as in English before the winter; distant kin, and so on). This kind of evidence has led to the widespread conclusion that spatial representation, both linguistic and cognitive, naturally underlies and informs the representation of other domains, in a relation that is explicitly understood as metaphorical (Lakoff 1980, Langacker 1987). But the similarity between the linguistic representation of space and that of other domains may be present at the level of the nature of the relationships which are involved (Gentner 1983, Danziger 1996) rather than at the lexical level. I will demonstrate here that we may see profound analogies between the language of space and that of other domains, even when there is no vocabulary in common across the domains. The analogies in question therefore do not clearly have the status of metaphors.

I will apply the distinctions of a four-part spatial frame of reference typology (Danziger 2010) to the language of temporal sequence, arguing that the two

\footnotetext{
${ }^{1}$ My thanks are due to the Mopan and Chol speakers whose expertise, both explicit and implicit, informs the conclusions of this paper. I am also deeply grateful to Lydia Rodriguez for permission to publish the words and gestures of example (8). Any infelicities in the presentation or interpretation of that material are my own responsibility. A great debt is owed to the members of the Cognitive Anthropology Research Group of the Max Planck Institute for Psycholinguistics 19911998, and to my colleagues in the Linguistic Anthropology Seminar at the University of Virginia. Finally, I thank the organizers of the 2013 Meetings of the Berkeley Linguistics Society.
} 


\section{Eve Danziger}

intersecting conceptual dichotomies which make up the four cells of the spatial typology have precise analogies in the literature which discusses the language of time. This means that the two-by-two matrix of the four-part spatial typology can also be used to delineate four types of temporal reference, which in turn should have logical and cognitive properties that parallel the four types of spatial reference. I'll look at an example of the gestures that accompany speech in a Mayan language, literally to see that the proposed analogies hold. I'll conclude that in the relational analogy between space and other domains, space itself does not emerge as primary or basic relative to the others. Instead it is the social-subjective situation of speech which plays this pivotal role.

\section{Extrinsic and Intrinsic Frames of Spatial Reference}

Consider the following simple scene: ${ }^{2}$

Man and Tree scene
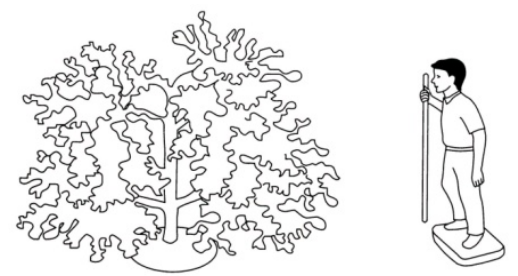

Now consider the upside-down scene below. The question is, does Figure 2 represent the same scene as the one shown in Figure 1? To solve this kind of problem, many people (Shepard and Cooper 1986) mentally rotate the second scene through an invisible medium external to it, which we can call "space." Once the two scenes are mentally oriented the same way, it is possible to visually assess them, and consider whether a spatially anchored proposition true of one scene is also true of the other: for example whether in both cases the tree is to the left of the man. A different strategy however (Just and Carpenter 1985), makes use of the internal parts of the scene, in a way which does not require mental rotation through any invisible external medium. In this case, the proposition to be evaluated for both scenes would be something like the tree is in front of the man.

\footnotetext{
${ }^{2}$ Figure 1 and the manipulations thereof in Figures 2 and 3 are copyright of the Cognitive Anthropology Research Group at the Max Planck institute for Psycholinguistics, and are reprinted here with permission Figures 6-8 are copyright of Eve Danziger and are printed here with permission.
} 

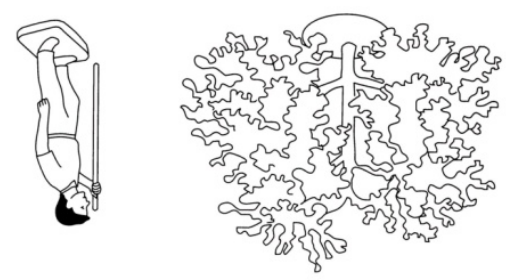

Two alternative frames of reference can thus be used to solve the puzzle. Let's call them, respectively, Extrinsic and Intrinsic frames of reference (O'Meara and Pérez Báez 2011). These two types of frames have some components in common. In both cases, there is an item whose location is being specified (here, the tree), which we can call the Figure (Talmy 1983). And in both cases there is another item in terms of which the Figure is being located (the man), which we can call the Ground (Talmy 1983). But Intrinsic and Extrinsic frames of reference also have some interestingly different components, and consequently some different logical and semantic properties (cf. Levelt 1984). In particular, the Intrinsic strategy may yield a solution to the puzzle exemplified in Figures 1 and 2 which the view from an Extrinsic frame of reference would reject. This would happen, for example, in the case where the second, upside-down scene actually showed a mirror-image of the original (Levinson and Brown 1994, Danziger 1996, 1999). In that case, the tree might still be in front of the man but it would not be to the left of the man once the two scenes were positioned in identical orientation with respect to the viewer.

(3) Mirror-image of Upside-down Man and Tree Scene.

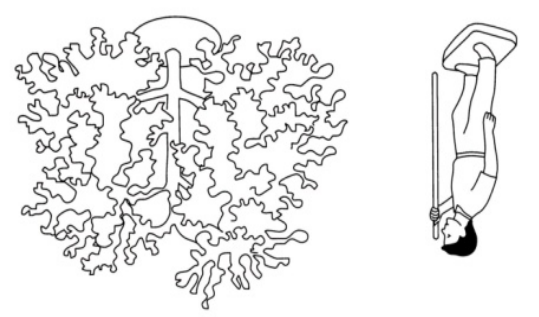

The mirror-image immunity of Intrinsic frames of reference is due to the fact that propositions formulated exclusively in Intrinsic frames do not make use of any reference points external to the Figure-Ground scene. Propositions framed in Extrinsic frames of reference on the other hand, criterially include a third component in addition to Figure and Ground, which is easily distinguishable from both, 


\section{Eve Danziger}

and which is used (among other things) to distinguish mirror-image reflections from one another (Van Cleve and Frederick 1991). This third point is one which we can call an Anchor. It is the zero point from which the vector that runs from the Ground toward the Figure originates. So, in the tree is to the left of the man as applied to Figure 1, 'leftness' is calculated not from the tree or from the man, but from one of the participants in the viewing/ speaking scene. As long as that participant Anchor does not him or herself rotate, this point will remain fixed even if the components of the Figure-Ground scene undergo inversion. This is what allows for the calculation that a scene and its mirror-image reflection are distinct -- a key hallmark of Extrinsic frames of reference.

All propositions framed within Extrinsic frames of reference include the three distinct components of a Figure, a Ground, and an Anchor which is separate from both. Extrinsic frames are sometimes called "Ternary" frames for this reason. Propositions framed within Intrinsic frames of reference have Anchors too - they clearly also specify a vector from which Figure is located with respect to Ground, and this vector must have a starting point. But in Intrinsic frames, by definition, the Anchor is identified with the Ground object itself - often, as in our example, with a part or facet of the Ground entity (front). So propositions framed in Intrinsic terms only have two distinct components: the Figure, and a Ground which also functions as the Anchor. Sometimes Intrinsic frames are called "Binary" frames for this reason.

\section{Allocentric and Egocentric Frames of Spatial Reference}

As an alternative to anchoring the Extrinsic spatial proposition in a speech participant's body (left), a geographical landmark or an abstract cardinal point may also be used as a scene-external Anchor. We might calculate, for example, that the tree was south or seawards or downstream of the man in Figure 1 (Haviland 1998). Extrinsic Anchors, in short, can be either Egocentric (inside the speech situation), or Allocentric (outside the speech situation). Similarly, the spatial Anchor of an Intrinsically framed proposition may be located either outside the speech situation (Allocentric) or within it (Egocentric). Since in Intrinsic frames the Ground is by definition identical to Anchor, Allocentric Intrinsic propositions have their Anchor - and therefore also their Ground - outside the speech situation (the tree is in front of the man) whereas Egocentric Intrinsic propositions have their Anchor and therefore also their Ground - within the speech situation (the tree is in front of me).

The insight that Extrinsic frames were to be defined on the basis of the speech-situatedness of Anchor, rather than on that of Ground has been immensely important in developing the precursors to the current typology (Levinson 1996). This operating rule means, for example, that a proposition such as The tree is north of me belongs in an Extrinsic frame of reference (Anchor in cardinal 
direction grid: north), despite the fact that it makes explicit reference to a speech situation participant. But this insight was not at first extended to the Intrinsic frames of reference (Pederson et al. 1998, Levinson 2003). Researchers have for some time been operating with the three-part typology (Relative, Absolute, and 'Intrinsic') that results. But applying the logical distinction between Egocentric and Allocentric Anchors to the Intrinsic as well as to the Extrinsic frames to produce a clear two by two matrix not only accords better with the rotation sensitivities that motivate the typology (Danziger 2010), but, as we will see, clarifies the possibilities for analysis of space-time mappings.

\section{$4 \quad$ A Four-Part Typology}

Two separate dichotomies have been identified which distinguish among different spatial frame of reference types involving Figures located with respect to Grounds. First, the vector from Ground to Figure may be calculated from an Anchor point within the Figure-Ground scene itself (Intrinsic), or from somewhere outside that scene (Extrinsic). Second, the Anchor may be located either within the speech situation (Egocentric) or elsewhere (Allocentric). These two dichotomies are in principle independent of one another, and yield four distinct outcomes. Figure 4 maps these outcomes, using the conventional nomenclature for the Extrinsic frames of reference ('Absolute/ Relative') which has been established in the earlier, three-part versions of similarly based typologies (Pederson et al. 1998, Levinson 2003). Speech-situated deictic demonstratives and locatives (e.g. over there!) may in most cases be typed as belonging to the Direct frame, as long as their obligatory accompanying vector-specifying pointing gestures are considered part of the overall spatial proposition (Danziger 2010).

\subsection{Spatial Language and Conceptualization}

Languages differ in the extent to which the different frame of reference types are likely to be spontaneously employed in a given spatial reference context (Pederson et al. 1998). For example, Mopan Maya, an indigenous language of Eastern Central America, uses only Intrinsic Frames of Reference to refer to FigureGround relations which are arrayed across the speaker's line of vision (Danziger 1999). Example (5) shows a representative Mopan utterance used to describe an arrangement like that in Figure 1.

The existence of languages like Mopan demonstrates that, while Intrinsic frames of spatial reference are present in every language, Extrinsic ones are historically and typologically optional. Intrinsic frames of spatial reference in language are also early and spontaneously acquired by children, whereas Extrinsic ones - if they are acquired at all -- come later in childhood, and often require 


\section{Eve Danziger}

explicit instruction (Piaget 1928, de León 1994, Danziger 1998). Of the two

(4) Table of Four Spatial Frame of Reference Types

\begin{tabular}{|l|l|l|}
\hline Where's the tree? & $\begin{array}{l}\text { Allocentric } \\
\text { Figure-Ground vector is } \\
\text { calculated from outside } \\
\text { the speech situation }\end{array}$ & $\begin{array}{l}\text { Egocentric } \\
\begin{array}{l}\text { Figure-Ground vector is } \\
\text { calculated from within } \\
\text { the speech situation }\end{array}\end{array}$ \\
\hline $\begin{array}{l}\text { Extrinsic } \\
\text { Figure-Ground vector is } \\
\text { calculated from beyond } \\
\text { the Ground }\end{array}$ & $\begin{array}{l}\text { Absolute } \\
\text { The tree is to the east of } \\
\text { the man. OR The tree is to } \\
\text { the north of me. }\end{array}$ & $\begin{array}{l}\text { Relative } \\
\text { The tree is to the right of } \\
\text { the man. }\end{array}$ \\
\hline $\begin{array}{l}\text { Intrinsic } \\
\text { Figure-Ground vector is } \\
\text { calculated from within } \\
\text { the Ground }\end{array}$ & $\begin{array}{l}\text { Object-Centered } \\
\text { The tree is in front of the } \\
\text { man. }\end{array}$ & $\begin{array}{l}\text { Direct } \\
\text { The tree is in front of me. } \\
\text { OR The tree is over there } \\
\text { (with pointing gesture) }\end{array}$ \\
\hline
\end{tabular}

Intrinsic frames, encoding of Direct spatial relations (in front of me) is earlier (Johnston and Slobin 1979, Danziger 1998). Direct-framed deictic demonstratives acquired across languages than that of Object-Centered ones (in front of the kettle) and locatives are acquired earliest of all (Tanz 1980).

(5) Mopan Maya (Danziger 1999). ${ }^{3}$ Allocentric Intrinsic Relations in Space $K a{ }^{\prime} \quad a-k a ̈ x-t \quad a \quad n e n e^{\prime} t z z^{\prime} u b^{\prime}$ COMP 2A-seek-TR DET little child 'You should find the little child $\begin{array}{llll}a & t \text { - } u \text {-taan } & k e^{\prime} e n-\varnothing & t^{\prime} o p=o \\ \text { REL } & \text { PREP-3A-chest } & \text { be_located-3B } & \text { flower }=\mathrm{EV}\end{array}$ who has the flower at his front.'

\footnotetext{
${ }^{3}$ Orthography in Mopan and Chol examples is that of the Academía de las Lenguas Mayas de Guatemala (England and Elliott 1990). Values are as in IPA except: ä = midcentral vowel; $x=$ voiceless alveopalatal fricative; $j=$ voiceless glottal fricative; $t z=$ voiceless alveolar affricate; $\mathrm{ch}=$ voiceless alveopalatal affricate. Apostrophe denotes glottal stop after a vowel, or glottalization of the preceding consonant. Interlinear glossing conventions follow the Leipzig conventions available at http://www.eva.mpg.de/lingua/resources/glossing-rules.php. Departures from these conventions are as follows: $\mathrm{A}=$ actor of transitive, argument of active intransitive, or possessor; $\mathrm{B}=$ patient of transitive, or argument of inactive intransitive; $\mathrm{ENCL}=$ enclitic; $\mathrm{EV}=$ prosodic echo vowel; $\mathrm{NPRF}=$ nonperfective; $\mathrm{PREP}=$ preposition .
} 


\section{Mapping Space and Time in a Four-Part Frame of Reference Typology}

At the conceptual level meanwhile, the particular configuration of spatial frames of reference that is used in a given language is correlated, Whorf-style (1956 [1940]), with the preferred strategies for spatial problem-solving among speakers of that language (Pederson et al. 1998, Levinson 2003). It is now understood for example, (Verhaege and Kolinsky 1991, Danziger and Pederson 1998) that the perceptual intuition that forms and their mirror images should be categorized as distinct is not an automatic maturational development in childhood, but must be non-necessarily acquired through explicit teaching or other cultural experience - such as that with Extrinsic frames of spatial reference. The cognitive correlates of Mopan Intrinsic-only habits of speech, for example, include mirrorimage immunity in non-linguistic perceptual categorization of both twodimensional and three-dimensional forms (Danziger 1999, 2011).

Typological and psychological lines of evidence thus converge to suggest that systematic relations of priority obtain worldwide among the four frames of the spatial frame of reference typology. A primary identity of Anchor, Ground and Speech Situation (Direct frame) is the first to appear, and forms expressing this configuration are universal across languages. In due course, the Direct frame is universally deconstructed to allow for a Ground/Anchor that is not the situation of speech (Object-Centered Frame). Subsequently, and only if it is culturally required, Ground may be separated from Anchor, to yield one or both of the Extrinsic Frames. Primary relations of identity among several key frame-of-reference components in Direct frame usage are thus progressively exploded to yield first Allocentric and then, optionally, Extrinsic frames.

\subsection{Temporal Relations}

If we are to use the spatial frame of reference typology to discuss the relational analogies between representations of space and those of time, it will be necessary to find equivalents for the three crucial components of frame of reference types in space: namely Figure, Ground and Anchor. It will also be important to maintain the key insight that the speech-situatedness of Anchor rather than that of Ground is always (and not just for Extrinsic frames) criterial in the typology. Reichenbach's (1947) terminology for temporal relations provides a useful starting point. His Narrated event (E: the moment to be located) is a good analogue of the spatial Figure, and his Reference event (R: the moment with respect to which a Narrated event is located) can be seen as an analogue of spatial Ground. In the English locution in (6), making breakfast is the 'Ground' event (R), against which sweeping, the 'Figure' event (E), is temporally located (see also Jacobson 1990, Kockelman 2007). 


\section{Eve Danziger}

\section{(6) English \\ I swept the house after I made breakfast.}

Reichenbach also provides us with another important concept - that of the Speech event (S: the moment of utterance). The grammatical past tense in example (6) temporally locates both Narrated (E) and Reference (R) events at a time prior to the moment of utterance. The vector-specifying after makes use of this speech-situated Anchor to locate the Figure (E: the sweeping) with respect to the temporal Ground (R: the breakfast-making). Reichenbach devotes considerable attention to working out the possibilities in which Reference event is and is not identical with Speech event in the English tense system. His work is thus especially valuable to the analogy with spatial frame of reference types, in that it makes the key typological move of clearly separating at least one value of the temporal equivalent of spatial Anchor (that is, the speech event, S) from that of the temporal equivalent of spatial Ground (R). In the terms which we have been using, Reichenbach was deeply concerned to separate Intrinsic $(S=R)$ temporal locutions from Extrinsic ones $(\mathrm{S} \neq \mathrm{R})$.

But Reichenbach does not discuss the possibility of an Extrinsic temporal Anchor which might be drawn from outside the speech situation (for example, perhaps a specific calendric event, or an event in mythical time). To get full compatibility with the spatial frame of reference typology, it will be necessary to add to the repertoire of Reichenbachian terms a higher-level concept, corresponding to Anchor more abstractly, of which S (speech event) will be only one possible value. Other theorists of temporal language (McTaggart 1908, Klein 2009) have seen more clearly the possibility of such a non-speech-situated temporal Anchor. McTaggart (1908), for example, famously separated the speech-situated "A-Series" of temporal expressions from the non-speech-situated "B-series," thus distinguishing what in the current terminology could be characterized as Egocentric and Allocentric frames of reference. In that tradition, however, the analogue of spatial Anchor is not always clearly distinguished from that of Ground, thus eliding the clear distinction between what we would like to call Extrinsic and Intrinsic frames of reference.

In the literature on the language of time, in short, two distinct dimensions of contrast are separately discussed (see Nunez and Cooperrider 2013 for recent review), without being brought into alignment with one another. To put it in the terms we have been using, on the one hand (Reichenbach 1947, Jakobson 1990, Kockelman 2007), the question of whether Ground is or is not identified with Anchor (the Extrinsic-Intrinsic contrast) is thoroughly investigated, but any extrinsic Anchor is always understood to be speech-situated (Egocentric). On the other hand (McTaggart 1908, Klein 2009), the question of whether the Anchor is or is not speech-situated (the Allocentric-Egocentric contrast) is closely explored, but less attention is paid to the relations of Anchor with Ground. 
We can marry these two axes, thus creating a two-by-two matrix for sequence in time that is directly analogous to the four-part frame of reference typology for location in space. Figure 7 presents this arrangement. Preserving the analogy with Figure 4, notional names (Eternal, Personal, Event-related, and Instantiated) are proposed for the four temporal frame of reference types that result. (While this arrangement clearly does not exhaust the possible avenues along which the linguistics of time can be examined (Comrie's (1985) distinction between Absolute and Relative tenses for example, is not captured by Figure 7, and the question of "movement through" time (Tenbrink 2011) is also not addressed), this matrix incorporates many of the existing key understandings about language and time, while also bringing those understandings into clearer relation with one another.

(7) Table of Four Temporal Frame of Reference Types

\begin{tabular}{|l|l|l|}
\hline When? & $\begin{array}{l}\text { Allocentric } \\
\text { Narrated event to Refer- } \\
\text { ence event vector is } \\
\text { calculated from outside } \\
\text { the speech situation }\end{array}$ & $\begin{array}{l}\text { Egocentric } \\
\text { Narrated event to Refer- } \\
\text { ence event vector is } \\
\text { calculated from within } \\
\text { the speech situation }\end{array}$ \\
\hline $\begin{array}{l}\text { Extrinsic } \\
\text { Narrated event to Refer- } \\
\text { ence event vector is } \\
\text { calculated from beyond } \\
\text { the Reference event }\end{array}$ & Eternal February 15, 2013. & after breakfast. \\
\hline $\begin{array}{l}\text { Intrinsic } \\
\text { Narrated event to Refer- } \\
\text { ence event vector is } \\
\text { calculated from within } \\
\text { the Reference event }\end{array}$ & $\begin{array}{l}\text { Event -Related } \\
\text { as soon as breakfast is }\end{array}$ & Instantiated \\
right now.
\end{tabular}

I now proceed to use what is already known about spatial conceptualization in the four frames to consider whether the parallel mapping of time and space in this way has psychological reality. In particular, I follow out the consequences of the fact that in spatial reference, propositions formulated in Intrinsic frames of reference are characterized by immunity to mirror-image reversal.

\section{Frame of Reference Conceptualization in the Language of Time}

Temporal reference in Yucatec Maya (Bohnemeyer 1998) and in Chol Maya (Rodriguez 2014) has in recent years been fully described. In many cases of 


\section{Eve Danziger}

temporal reference in these tenseless languages, the temporal Anchor from which the relation of the Reference event can be calculated to the Narrated event is located purely in the Reference event itself (Intrinsic). If, as in example (8) below, the Reference event is located outside the speech situation, the temporal locution can, in the terms of Figure 7, be characterized as Allocentric Intrinsic.

(8) Chol Maya (Rodriguez 2014). Allocentric Intrinsic Relations in Time

$$
\begin{array}{lll}
\text { tyech-e- } \varnothing & k \text {-juch'- } \varnothing-e & k-s a ' \\
\text { begin-TR.PRF-3B } & \text { 1A-grind-INTR.NPRF-ENCL } & 1 \text { A-pozol } \\
\text { 'I begin to grind corn (for) my pozol ('corn-based drink').' }
\end{array}
$$

$\begin{array}{lll}\text { tyech-e- } \varnothing & k \text {-juch'- } \varnothing-e & k \text {-waj } \\ \text { begin-TR.PRF-3B } & \text { 1A-grind-INTR.NPRF-ENCL } & \text { 1A-tortilla } \\ \text { 'I begin to grind corn (for) my tortillas.' } & \end{array}$

Mi kaj tyi pechom

IPFV start PREP shape.tortilla

'I start to shape tortillas.'

Ujty-i- $\varnothing \quad$ pechom,

Finish-INTR.PRF-3B shape.tortilla

'Tortilla-shaping being finished,
$M u=x$
kaj
tyi misuj-el
pejtyel
jiñi
$\mathrm{IPFV}=$ already start
PREP sweep-NMLZ everything
DET
I at once start sweeping and everything - that's it.'

Recall that when dealing with spatial representations, the mirror-image immunity that attaches to locutions like that in example (5) by virtue of its Intrinsic structure extends to the cognitive level (Danziger 1999, 2011), so that Mopan speakers like the author of example (5) intuitively classify mirror-image forms and their reflections as alike. If the frame of reference analogy extends to conceptualization in the temporal realm, then the sequential relation that connects the events of example (8) should show an analogous immunity.

Spontaneous speech-accompanying gesture that accompanies talk could be valuable in literally showing us whether this is the case. In Mayan languages as elsewhere, spontaneous gestures pattern with choice of spatial frame of reference (Haviland 1993, Danziger 2010, LeGuen 2011). And since gesture takes place in space, we can use it to identify the type of cognitive frame of reference that is in play, even when spatial language is not employed (Kita et al. 2001). It should be possible to examine the literally spatial configuration of gestures that accompa- 
nies temporal speech for the logical characteristics which we know to distinguish among the different frame of reference types in space. More concretely, and with specific reference to (8), if the fact that tortilla-shaping comes after corn-grinding is spatialized in any one gestural direction, this should not necessarily mean that a gesture encoding the fact that sweeping comes after tortilla-shaping must continue in the same direction. A reverse direction (mirror image) would do just as well.

The Chol utterance in example (8) was in fact accompanied by a series of gestures which appear to indicate the time relations between the events (Rodriguez 2014). The gestures were not motivated by props and locations in the co-present context and do not iconically represent the activities named. The first event (juch' 'grinding corn') is verbalized twice (grinding corn for drink, grinding corn for food), and is accompanied by two beat gestures, made in rhythmic succession in the same location.

(9) 'I start to grind for tortillas'

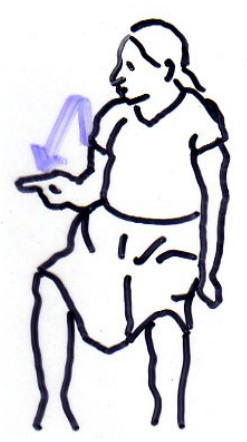

The second event (pechom 'shaping tortillas') is gestured far to the right -arriving there via an arc-shaped, clearly non-beat gesture.

(10) 'I start to shape tortillas'

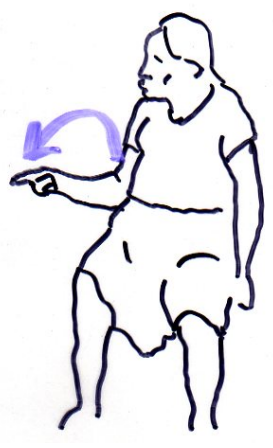

The earlier event in the sequence (grinding) is thus depicted gesturally to the left of the later event (shaping tortillas). If this sequence shows mirror-image distinction, we would now expect that the third event, the end of making tortillas, which is coincident with the sweeping event (misuj-el), would be gestured even 


\section{Eve Danziger}

further to the right. But this third event is actually gestured with another marked arc gesture back to the left, thus showing mirror-image immunity in the gesturing of sequential temporal relations (Figure 11).

(11)

\section{'Tortilla-making being finished,'}

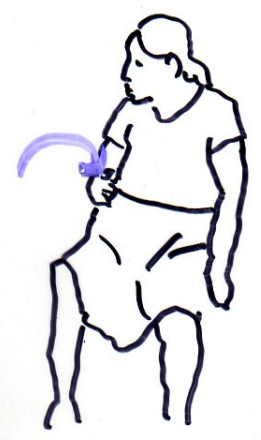

This example is part of a significant corpus of similar data (Rodriguez 2014) which is dedicated to making a wider point about the nature of time concepts in Chol (see also Le Guen and Pool Balam 2012 for related data from Yucatec Maya). There are no explicit spatial metaphors in this particular example, but the gesture configuration is enough to demonstrate that this temporal locution has the logical-conceptual properties (mirror-image equivalence) which are associated with its corresponding frame of reference type (Allocentric Intrinsic) in the spatial typology.

\section{Conclusion}

I have shown that the heuristic of a four-part spatial Frame of Reference typology can be used to uncover profound analogies between representations of space and those of time, even where lexical metaphor is not involved. Evidence from speech-accompanying gesture suggests that the analogies so uncovered have psychological reality. But the analogy between space and time here gives no evidence that space has the privileged or basic position. Rather, the analogy is evidence of structural commonalities in how people talk and think about relationships, which go beyond the content of any one relational domain. Space emerges as only one a series of parallel domains which have in common that they exploit the intersection of two dichotomies to unpack the contrast possibilities inherent in the Egocentric Intrinsic frame of reference case -- that primal case in which Ground and Anchor both converge on the situation of speech. And that suggests, finally, that the baseline for the type of linguistic cognition we are talking about is not grounded in physiological experience of the physical world, but in interactional experience of the sociological one. 
Mapping Space and Time in a Four-Part Frame of Reference Typology

\section{References}

Bohnemeyer, Jürgen. 1998. Temporal Reference from a Radical Pragmatics Perspective: Why Yucatec Does Not Need to Express 'After' and 'Before'. Cognitive Linguistics 9(3): 239-282.

Comrie, Bernard. 1985. Tense. Cambridge: Cambridge University Press.

Danziger, Eve. 2011. Distinguishing Three-Dimensional Forms from their MirrorImages: Whorfian Results from Users of Intrinsic Frames of Linguistic Reference. Language Sciences 33(6): 853-867.

Danziger, Eve. 2010. Deixis, Gesture and Cognition in Spatial Frame of Reference Typology. Studies in Language 34(1):167-185.

Danziger, Eve. 1999. Language, Space and Sociolect: Cognitive Correlates of Gendered Speech in Mopan Maya. In Catherine Fuchs and Stéphane Robert eds., Language Diversity and Cognitive Representations, 85-106. Amsterdam, NL: John Benjamins.

Danziger, Eve. 1998. Getting Here from There: The Acquisition of Point of View in Mopan Maya. Ethos: Journal of the Society for Psychological Anthropology 26(1):48-72.

Danziger, Eve. 1996. Parts and their Counter-Parts: Social and Spatial Relationships in Mopan Maya. Journal of the Royal Anthropological Institute (N.S.), incorporating MAN 2(1):67-82.

Danziger, Eve, and Eric Pederson. 1998. Through the Looking-Glass: Literacy, Writing Systems and Mirror-Image Discrimination. Written Language and Literacy 1(2):153-64.

De León, Lourdes. 1994. Explorations in the Acquisition of Geocentric Location by Tzotzil Children. Linguistics 32(4-5): 857-884

England, Nora C., and S. R. Elliot. 1990. Lecturas Sobre la Lingüistica Maya. Guatemala: Centro de Investigaciones Regionales de Mesoamérica.

Gentner, Dedre. 1983. Structure-mapping: a theoretical framework for analogy. Cognitive Science 7:155-170.

Haviland, John B. 1998. Guugu Yimithirr cardinal directions. Ethos: Journal of the Society for Psychological Anthropology 26 (1):25-47.

Haviland, John B. 1993. Anchoring, Iconicity, and Orientation in Guugu Yimithirr Pointing Gestures. Journal of Linguistic Anthropology 3: 3-45.

Jakobson, Roman. 1990. On Language. Linda R. Waugh and Monique MonvilleBurston eds., Cambridge Mass: Harvard University Press.

Johnston, Judith R. and Dan Slobin. 1979. The Development of Locative Expressions in English, Italian, Serbo-Croatian and Turkish. Journal of Child Language 6:529-545.

Just, M. A. and P.A. Carpenter. 1985. Cognitive Coordinate Systems: Accounts of Mental Rotation and Individual Differences in Spatial Ability. Psychological Review 92(2):137-172. 


\section{Eve Danziger}

Kita, Sotaro, Eve Danziger and Christel Stolz. 2001. Cultural Specificity of Spatial Schemas as Manifested in Spontaneous Gestures. In Meredith Gattis, ed., Spatial Schemas in Abstract Thought, 115-146. Cambridge, MA: MIT Press.

Klein, Wolfgang. 2009. How Time is Encoded. In Wolfgang Klein and Ping Li eds., The Expression of Time, Berlin: Mouton de Gruyter.

Kockelman, Paul. 2007. Meaning and Time: Translation and Exegesis of a Mayan Myth. Anthropological Linguistics 49 (3/4):308-397.

Lakoff, George. 1980. Metaphors We Live By. Chicago: University of Chicago Press

Langacker, Ronald W. 1987. Foundations of Cognitive Grammar, Volume I, Theoretical Prerequisites. Stanford: Stanford University Press.

Le Guen, Olivier. 2011 Modes of Pointing to Existing Spaces and the Use of Frames of Reference. Gesture 11(3):271-307.

Le Guen, Olivier and Lorena I. Pool Balam. 2012. No metaphorical Timeline in Gesture and Cognition among Yucatec Mayas. Frontiers in Cultural Psychology 3:1-15.

Levelt, Willem J. M. 1984. Some Perceptual Limitations on Talking about Space. In A. van Doorn, W. de Grind, and J. Koenderink eds., Limits in Perception, 323-358. Utrecht: VNU Science Press.

Levinson, Stephen C. 2003. Space in Language and Cognition. Cambridge: University Press.

Levinson, Stephen C. 1996. Frames of Reference and Molyneux's Question: Cross-Linguistic Evidence. In: Bloom, P., Peterson, M., Nadel, L., Garrett, M. eds., Language and Space, 109-169. Cambridge, MA: MIT Press.

Levinson, Stephen C. and Penelope Brown. 1994. Immanuel Kant among the Tenejapans: Anthropology as Empirical Philosophy Ethos: Journal of the Society for Psychological Anthropology 22: 3-41.

McTaggart, J. Ellis. 1908. The Unreality of Time. Mind 17:457-474

Nuñez, Rafael and Kensy Cooperrider. 2013. The Tangle of Space and Time in Human Cognition. Trends in Cognitive Sciences 17 (5):220-229.

O’Meara, Carolyn and Gabriela Pérez Báez. 2011. Spatial Frames of Reference in Mesoamerican Languages. Language Sciences 33(6): 837-852.

Pederson, Eric, Eve Danziger, Stephen C. Levinson, Sotaro Kita, Gunter Senft and David P. Wilkins. 1998. Semantic Typology and Spatial Conceptualization. Language 74(3): 557-589.

Piaget, Jean. 1928. Judgment and Reasoning in the Child, M. Warden, trans. New York: Harcourt, Brace and Company.

Reichenbach, Hans. 1947. The Tenses of Verbs. Elements of Symbolic Logic, 287298. NY: The Free Press.

Rodriguez Cuevas, Lydia. 2014. Thinking Gesture: Gesture and Speech in Chol Maya. Ph.D. dissertation, Department of Anthropology, University of Virginia. 
Shepard, R.N. \& L.A. Cooper. 1986. Mental Images and their Transformations. Cambridge, MA/ London: MIT Press

Talmy, Len. 1983. How Language Structures Space. In H. Pick and L. Acredolo eds., Spatial Orientation: Theory, Research, and Application. New York: Plenum Press.

Tanz, Christine. 1980. Studies in the Acquisition of Deictic Terms. Cambridge: Cambridge University Press.

Tenbrink, Thora. 2011. Reference Frames of Space and Time in Language. Journal of Pragmatics 43:704-722

Van Cleve, J., Frederick, R. (eds.). 1991. The Philosophy of Left and Right. Dordrecht, Boston, London: Kluwer Academic Publishers.

Verhaeghe, Arlette, and Régine Kolinsky. 1991. Discriminação entre figuras orientadas em espelho em função do modo de apresentação em adultos escolarizados e adultos iletrados. Actas das I Jornadas de Estudo dos Processos Cognitivos, Sociedade Portuguesa de Psicologia, Lisbon.

Whorf, Benjamin Lee. 1956 [1940]. Science and Linguistics. In J.B. Carroll, ed., Language, Thought, and Reality: Selected Writings of Benjamin Lee Whorf, 207-219, Cambridge MA: MIT Press.

Eve Danziger

University of Virginia

Department of Anthropology

P.O. Box 400120

Charlottesville, VA 22904-4120

ed8c@virginia.edu 